\title{
Carbon emission efficiency measurement and influencing factor analysis of nine provinces in the Yellow River basin: based on SBM-DDF model and Tobit-CCD model
}

\author{
Yuan Zhang ${ }^{1} \cdot{\text { Xiangyang } X u^{1,2}}^{1}$
}

Received: 12 October 2021 / Accepted: 4 January 2022 / Published online: 13 January 2022

(c) The Author(s), under exclusive licence to Springer-Verlag GmbH Germany, part of Springer Nature 2022

\begin{abstract}
The Yellow River basin (YRB) is China's most critical energy consumption and coal production area. The improvement of carbon emission reduction efficiency in this area is the key for the Chinese government to achieve the 2030 carbon peak and 2060 carbon neutral ("30.60"). Given this, this study first calculates the carbon emission efficiency of YRB from 2005 to 2019 based on the slack-based measured directional distance function (SBM-DDF) model and combined with Malmquist-Luenberger (ML) index and decomposes the carbon emission efficiency of each province. Then, a panel Tobit model with random effect is constructed to measure the influencing factors and their influence degree of carbon emission efficiency of YRB. Finally, the main influencing factors are selected, and policy suggestions on how to improve the carbon emission efficiency of each province are put forward with the help of the coupling coordination degree (CCD) model. The results show that first, the carbon emission efficiency of each province is significantly different, but it shows a fluctuating upward trend on the whole. Second, the reasons for the rise or decline of the ML index in different provinces are different. Therefore, the development strategies of different provinces should be formulated from the perspective of accelerating technological progress and improving technical efficiency. Finally, the calculation results of influencing factors and coupling coordination degrees show that provinces with high coupling coordination degrees should focus on developing per capita power consumption and controlling per capita power consumption to consolidate the actual urbanization process and industrial structure adjustment. Provinces with low coupling coordination degrees should focus on maintaining the urbanization process and increasing the development of the tertiary industry. Therefore, to fundamentally reduce carbon emissions in YRB areas, we need to consider implementing differentiated emission reduction schemes based on national strategic objectives and in combination with the development characteristics of various provinces.
\end{abstract}

Keywords Yellow River basin · Carbon emission efficiency · SBM-DDF model · Malmquist-Luenberger index · Influencing factors $\cdot$ Coupling coordination degree

\section{Introduction}

COVID-19 has aroused people's profound reflection on the relationship between man and nature. Global climate governance should be paid more attention to the whole society

Responsible Editor: Philippe Garrigues

Xiangyang Xu

3199056941@qq.com

1 School of Management, China University of Mining and Technology-Beijing, Beijing 100083, China

2 Center for Resources and Environmental Policy Research, China University of Mining and Technology-Beijing, Beijing 100083, China in the future. On December 12, 2020, President Xi Jinping's statement at the Climate Ambition Summit showed that China had made essential contributions to the Paris Agreement as China's largest developing country. In September 2020, China announced that it would comprehensively enhance the independent national contribution, increase carbon emission reduction, strive for $\mathrm{CO}_{2}$ peak before 2030, and reduce carbon intensity by $65 \%$ over 2005 ; the proportion of non-fossil energy in primary energy consumption will rise to $25 \%$, forest stock will increase by 6 billion cubic meters, the total installed capacity of wind power and solar power generation will strive to reach more than 1.2 billion kilowatts, and carbon neutrality will be achieved before 2060 (Xi 2021). Given such an emission reduction target, the YRB, which relies on extensive development, will face 
tremendous pressure on emission reduction. And different regions will also meet additional requirements on emission reduction. Therefore, as China's vital energy and chemical industry base, ecological protection region, and economic region, the YRB is of great significance to China's overall realization of ecological civilization construction ( $\mathrm{Li}$ et al. 2012). Although breakthroughs have been made in the environmental structure and environmental governance of the YRB under the attention of the government (Jin 2019), the fragile ecological environment and water shortage in the YRB are still prominent contradictions, so they are still studied and discussed in academic circles (Liu et al. 2020a; Ma et al. 2012). Various provinces in the region have significant development modes, and conflicts between resource endowment, economic development, and environmental problems are relatively prominent. Therefore, how to achieve lowcarbon and sustainable development of the YRB is the key to achieving high-quality growth (Lu and Sun 2019).

The Yellow River is the mother river of the Chinese nation. The YRB mainly includes nine provinces, Shanxi, Inner Mongolia, Shandong, Henan, Sichuan, Shaanxi, Gansu, Qinghai, and Ningxia, and its geographical location is shown in Figure 1. The ecological protection and highquality development of the YRB have become a national strategy as crucial as the integrated development of the Pearl River Delta and the Yangtze River Delta; the coordinated development of Beijing, Tianjin, and Hebei; and the construction of Guangdong, Hong Kong, and Macao Bay Area. The party and government attach great importance to the development of the YRB, conducive to promoting regional sustainable development (Zhang et al. 2020). As the YRB is a solid energy base in China, it has a large population base, accelerated urbanization, high economic density and other development characteristics (Zhao et al. 2020), therefore, the global carbon emission reduction of the YRB will bear a significant responsibility in China's overall carbon emission reduction and will become the focus of academic circles in the future (Zhang 2020; Wang et al. 2020; Yuan et al. 2020).

During the study period from 2005 to 2019 , the ratio of population in the YRB to the total population of the whole country decreased slightly from 31.15 to $30.12 \%$, the proportion of regional GDP increased slightly from 25.29 to $25.53 \%$, the balance of energy consumption decreased from 39.62 to $34.76 \%$, and the ratio of carbon emission decreased from 32.30 to $31.12 \%$, as shown in Figure 2. It can be seen that the carbon emission contribution of the YRB is much more significant than the economic contribution, so the region belongs to a high carbon emission region. The carbon emissions and energy consumption of this region account for more than one-third of the total carbon emissions of China. Therefore, whether the YRB can take the lead in formulating reasonable and practical carbon emission reduction policies is the key for China to achieve the carbon emission reduction target in 2030 ( $\mathrm{Li}$ et al. 2020a).

On this basis, this paper takes the YRB as the research object. Firstly, based on the SBM-DDF model of unexpected output, the carbon dioxide emission efficiency of YRB regions from 2005 to 2019 is calculated. Then, combined with the ML index, carbon emission efficiency's temporal and spatial evolution characteristics are analyzed from static and dynamic perspectives. Finally, the main influencing factors and their influence degree affecting the regional carbon emission efficiency are detected. Combined with the introduction of the coordination coupling degree model, the targeted policy suggestions for different provinces to improve the carbon emission efficiency are put forward.

The rest of the paper is designed as follows. The second section summarizes the relevant literature review. The third section introduces the research methods and data sources. The fourth section makes an empirical analysis of the research results. The fifth section mainly presents the research conclusions and policy recommendations. The sixth section 6 discusses the differences and advantages of this paper.

\section{Literature review}

With the world's attention to climate change, "low carbon," "emission reduction," and other topics have become the focus of academic research. However, improving the efficiency of regional carbon emission is one of the critical issues to control carbon emission. There are two commonly used methods to measure carbon emission efficiency, and one is the parametric method, the other is the nonparametric method. The former's disadvantage is that it needs to assume the efficiency boundary, so this method cannot deal with the multi-output problem well. The most commonly used way in the latter approach is data envelopment analysis (DEA). Compared with the former, this method does not need to assume the efficiency boundary and has significant advantages in dealing with multi-output problems. Therefore, it has been widely used and extended in the academic community. Many scholars use the DEA model to study the carbon quota allocation at different countries, Chinese provinces, and Chinese industries and develop targeted policy suggestions on the imbalance of regional development (Ramanathan 2002; Zhou et al. 2014; Zhang and Hao 2017; Zhang 2013; Zhuang et al. 2016). Chang and Zhang (2013) and Wang and $\mathrm{He}$ (2017) constructed the DEA-SBM model and Omni-directional distance function model, respectively, to evaluate the carbon emission reduction efficiency and cost of local and national transportation industry and put forward targeted transportation industry emission reduction 


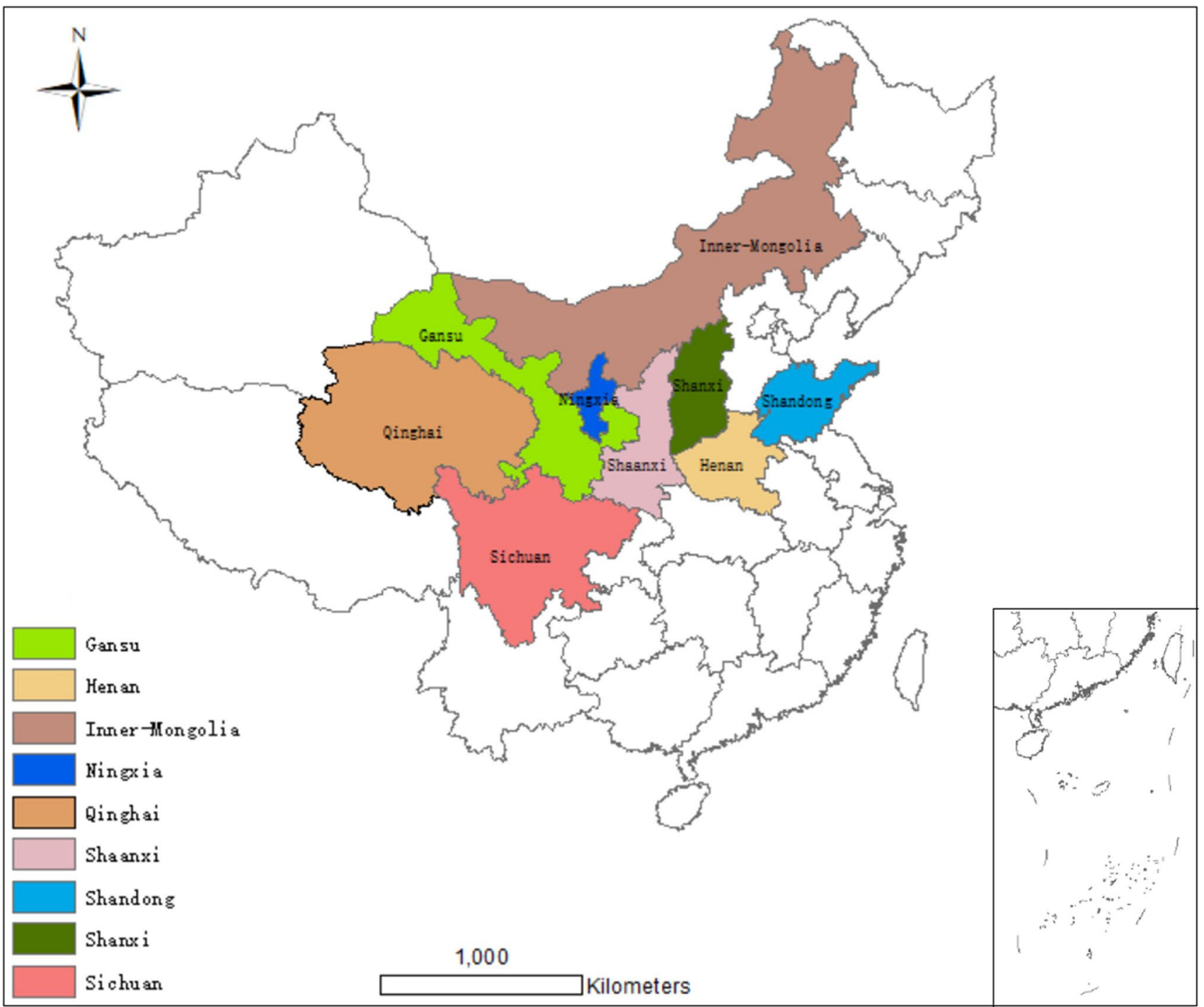

Fig. 1 The geographical location of the YRB in China

measures, which also laid a good foundation for the construction of this model.

Research on carbon emission efficiency mainly focuses on calculating efficiency value, spatial difference analysis, and influencing factors in the existing literature. With the deepening of the study, the measurement of total factor regional carbon emission efficiency gradually replaces the single factor measurement and becomes an essential research topic. In terms of measuring efficiency, the two main popular research methods in academia are the SBM model and the directional distance function. Zhang (2021) studied the impact of environmental regulation on green industrial efficiency by using the non-radial SBM model. Cui and Varatharajan (2021) introduced non-radial and non-angular SBM models to measure logistics enterprises' transportation efficiency. Teng et al. (2021) and Yang et al. (2021) used a dynamic
SBM model to evaluate regional wastewater treatment efficiency and carbon emission efficiency after afforestation in China, respectively. Jiang (2021) used the SBM model to measure the efficiency of industrial land. And many scholars also used the directional distance function to measure efficiency. The traditional directional distance function is a radial and guiding method. When there are relaxation variables, the "radial" will overestimate the efficiency, while the "guiding" cannot consider the changes of input and output efficiency at the same time. Therefore, some scholars have combined data envelopment analysis with directional distance function in recent years, taking environmental pollution, energy consumption, and ecological damage as factor input or unexpected output. Thus, environmental efficiency (Xu et al., 2021), energy efficiency (Wang et al. 2019b), carbon emission performance ( $\mathrm{Li}$ et al. 2020a, b, c), and 
resource and environmental efficiency (Zhou et al. 2019) are measured and calculated.

To measure the carbon emission efficiency of the YRB region more effectively, this paper combines the advantages of the SBM model and directional distance function to construct a non-radial SBM-DDF model, which avoids the defects of traditional DEA methods. And combined with the ML index decomposition method, the main reasons affecting the rise or decline of the ML index in nine provinces in the YRB area are found. Finally, the influencing factors affecting YRB carbon emission efficiency are calculated. The coupling coordination degree model makes targeted policy suggestions for each province's carbon emission reduction strategies.

\section{Methodology and data sources}

\section{Methodology}

\section{Construction of the SBM-DDF model based on the unexpected output}

Most of the research methods used by academia in carbon emission efficiency are DEA methods. As an essential tool of efficiency research, the DEA model was initially proposed by operational research experts. It can determine the frontier of nonparametric effective production and evaluate the relative effectiveness of decision-making units with multiple input-output indicators. It has been widely applied in carbon emissions, land use, industry management, etc. However, the basic DEA methods do not include the unexpected output. Some studies treat it as input, which is easy to conflict with relevant theories intuitively. Therefore, some scholars began to introduce the extended model of DEA for indepth research. Miao et al. (2019) adopt the range adjusted measure data envelopment analysis (RAM-DEA) to measure the technical efficiency and productivity change in the provinces of China. Miao and Chen (2021) measure technological inefficiencies and productivity changes in China's "Three Regions and Ten Urban Agglomerations" based on data envelopment analysis, namely, the bounded adjustment measure (BAM-DEA) with additive structure.

With improved research methods, many scholars use the directional distance function model. That is, carbon emissions are measured as unexpected output. However, the traditional directional distance function has the radial and guidance of input and output, which will lead to the deviation between the measured value of carbon emission efficiency and the actual value. The model construction of this paper mainly refers to the research of Tone et al. (2020) and Wang et al. (2019a, b). To avoid the radial and directional deviation of the traditional directional distance function, a non-radial and non-directional SBM-DDF model proposed by the academic community in recent years makes up for the above defects. It can more truly measure the carbon emission efficiency. In addition, scholars put forward the superefficiency DEA model to further compare the efficiency differences between multiple decision-making units when they are effective:

1. Production possibility set including both "expected output" and "unexpected output" which is constructed. Suppose that the input factors, expected output, and unexpected output of each province $k$ in period $t$ are expressed as $\mathrm{X}=\left[\mathrm{x}_{1}, \cdots, \mathrm{x}_{\mathrm{n}}\right] \in \mathrm{R}_{\mathrm{n}}^{+}$, $\mathrm{Y}=\left[\mathrm{y}_{1}, \cdots, \mathrm{y}_{\mathrm{m}}\right] \in \mathrm{R}_{\mathrm{m}}^{+}, \mathrm{b}=\left[\mathrm{b}_{1}, \cdots, \mathrm{b}_{\mathrm{h}}\right] \in \mathrm{R}_{\mathrm{h}}^{+}$. Therefore, the output combination brought by the input vector $x$ of province $k$ in period $t$ can be expressed as $(y, b)$, and the model using the DEA method can be described as

$$
P^{t}\left(x^{t}\right)=\left\{\begin{array}{c}
\left(y^{t}, b^{t}\right) \sum_{\mathrm{k}=1}^{\mathrm{k}} z_{k}^{t} y_{k m}^{t} \geq y_{k m}^{t}, \forall m ; \\
\sum_{\mathrm{k}=1}^{\mathrm{k}} z_{k}^{t} b_{k h}^{t}=\mathrm{b}_{\mathrm{kh}}^{\mathrm{t}}, \forall h ; \\
\sum_{\mathrm{k}=1}^{\mathrm{k}} z_{k}^{t} x_{k n}^{t} \leq x_{k n}^{t}, \forall n ; \\
\sum_{\mathrm{k}=1}^{\mathrm{k}} z_{k}^{t}=1, z_{k}^{t} \geq 0, \forall k
\end{array}\right.
$$

where $z_{k}^{t}$ represents the weight of each cross-section observation value. When the production technology shows variable return to scale (VRS), it needs to meet the above formula $\sum_{\mathrm{k}=1}^{\mathrm{k}} z_{k}^{t}=1, z_{k}^{t} \geq 0$; if the production technology is a constant return to scale (CRS), this constraint can be ignored. Since CRS is selected in this paper, this constraint is ignored in the calculation.

2. Based on the research of Färe et al. (2007) and Fukuyama and Weber (2008), this paper uses the non-radial and non-angular SBM-DDF model based on unexpected output to calculate the temporal and spatial evolution characteristics of regional carbon emission efficiency differences. The model is constructed as follows:

$$
\begin{array}{r}
\vec{D}^{t}\left(x^{t k}, y^{t k}, b^{t k}, g^{x}, g^{y g}, g^{y b}\right)=\max _{s^{x}, y_{,}, b^{b}} \frac{1}{2}\left[\frac{1}{N} \sum_{\mathrm{n}=1}^{\mathrm{N}} \frac{S_{n}^{x}}{g_{n}^{x}}+\frac{1}{M+P}\left(\sum_{\mathrm{m}=1}^{\mathrm{M}} \frac{S_{m}^{y}}{g_{m}^{y}}+\sum_{\mathrm{h}=1}^{\mathrm{H}} \frac{\mathrm{s}_{\mathrm{h}}^{\mathrm{b}}}{\mathrm{g}_{\mathrm{h}}^{\mathrm{b}}}\right)\right] \\
\text { s. t. }\left\{\begin{array}{c}
\sum_{\mathrm{k}=1}^{\mathrm{k}} \mathrm{z}_{\mathrm{k}}^{\mathrm{t}} \mathrm{x}_{\mathrm{kn}}^{\mathrm{t}}+\mathrm{S}_{\mathrm{n}}^{\mathrm{x}}=\mathrm{x}_{\mathrm{kn}}^{\mathrm{t}}, \forall n ; \\
\sum_{\mathrm{k}=1}^{\mathrm{k}} \mathrm{z}_{\mathrm{k}}^{\mathrm{t}} \mathrm{y}_{\mathrm{km}}^{\mathrm{t}}-\mathrm{S}_{\mathrm{m}}^{\mathrm{y}}=\mathrm{y}_{\mathrm{km}}^{\mathrm{t}}, \forall m ; \\
\sum_{\mathrm{k}=1}^{\mathrm{k}} \mathrm{z}_{\mathrm{k}}^{\mathrm{t}} \mathrm{b}_{\mathrm{kh}}^{\mathrm{t}}+\mathrm{S}_{\mathrm{h}}^{\mathrm{b}}=\mathrm{b}_{\mathrm{kh}}^{\mathrm{t}}, \forall h \\
\mathrm{~S}_{\mathrm{n}}^{\mathrm{x}} \geq 0, \forall n ; \mathrm{S}_{\mathrm{m}}^{\mathrm{y}} \geq 0, \forall m ; \mathrm{S}_{\mathrm{h}}^{\mathrm{b}} \geq 0, \forall h
\end{array}\right.
\end{array}
$$

where $\left(\mathrm{x}^{\mathrm{tk}}, \mathrm{y}^{\mathrm{tk}}, \mathrm{b}^{\mathrm{tk}}\right)$, respectively, represent the input and output vectors of province $\mathrm{k}$; $\left(\mathrm{g}^{\mathrm{x}}, \mathrm{g}^{\mathrm{yg}}, \mathrm{g}^{\mathrm{yb}}\right)$, respectively, represent the direction vectors of input decrease, expected output increase, and unexpected output decrease. $\left(\mathrm{S}_{\mathrm{n}}^{\mathrm{x}}, \mathrm{S}_{\mathrm{m}}^{\mathrm{y}}, \mathrm{S}_{\mathrm{h}}^{\mathrm{b}}\right)$ represents the relaxation vector, and both are positive vectors, which means that the actual input and unexpected output are more significant than the boundary input and unexpected output, while the expected output is less than the boundary expected output, so $\mathrm{S}_{\mathrm{n}}^{\mathrm{x}}, \mathrm{S}_{\mathrm{m}}^{\mathrm{y}}, \mathrm{S}_{\mathrm{h}}^{\mathrm{b}}$ represents the scenarios of too much 
Fig. 2 The proportion of the YRB in China. (Data sources: calculated according to the China Statistical Yearbook from 2006 to 2020)

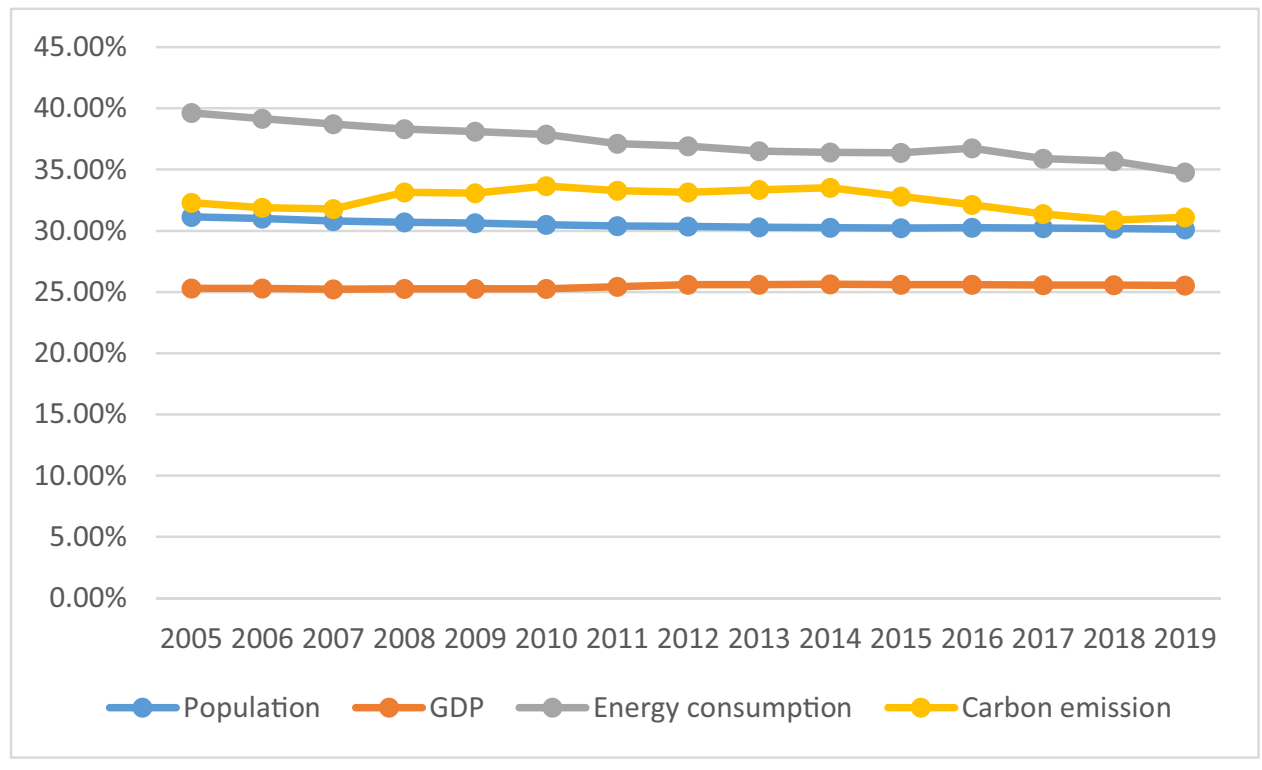

input, too little expected output, and too much-unexpected output, respectively.

\section{Malmquist-Luenberger index}

In this paper, the ML index is also used to analyze the change rate of carbon emission efficiency in the YRB. The time series dynamic analysis of regional carbon emission efficiency is carried out by introducing the ML index, mainly adopting the Malmquist-Luenberger index model constructed by Zhou et al. (2010). The specific formula is as follows:

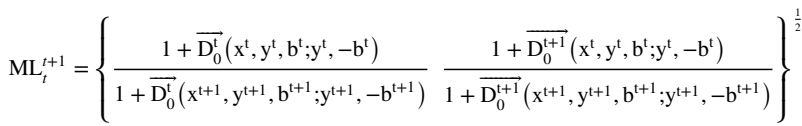

When the $\mathrm{ML}_{t}^{t+1}>1$,it indicates that total factor productivity level increases from $t$ to $t+1$; otherwise, when $\mathrm{ML}_{t}^{t+1}<1$, it indicates that productivity level decreases. The specific ML index decomposition results are as follows:
Conversely, when $T P C<1$, the decision-making unit is not ideal for the existing technological innovation. TEC is the change index of technical efficiency. When $T E C>1$, the technical efficiency has been improved. On the contrary, the technical efficiency needs to be improved.

\section{Construction of the Tobit model}

Scholars use different methods and models to analyze regional energy efficiency, carbon emission, coal resource efficiency, and green economic efficiency. Wang et al. (2021) introduced the LPI-LMDI model by incorporating the decomposition of the Luenberger productivity indicator (LPI) into the LMDI decomposition, profoundly analyzing the factors affecting greenhouse gas emissions changes Belt and Road countries. Xue et al. (2021) used the Tobit model to study the influencing factors of coal resource utilization efficiency in various provinces of China. Li et al. 2020b) use the dynamic DEA model and Tobit regression to study how income inequality affects the " 33 Belt and Road Initiative countries" energy efficiency. Dong et al.

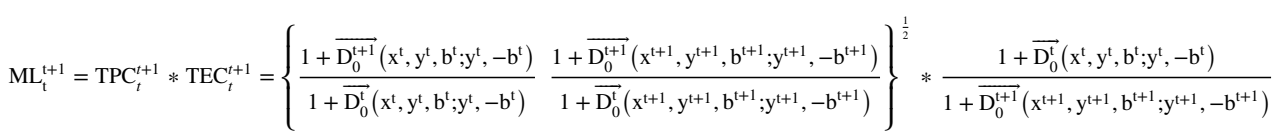

Among them, TPC represents the change index of technological progress. If TPC $>1$, it means that the closer the decision-making unit is to the production frontier, the technological progress will be improved (Liu et al. 2021; Cao et al. 2020; Liu et al. 2020b; Wang et al. 2020).
2020) apply the Tobit model to analyze the influencing factors of regional ecological efficiency in China.

To further explore the influencing factors affecting the difference in carbon emission efficiency of YRB, the Tobit model is introduced in this paper. Since the carbon emission 
efficiency calculated in this paper is mainly between 0.20 and 1.46, the estimation of the ordinary least squares regression method may bring biased results. Because the carbon emission efficiency values are more significant than zero and have the characteristics of non-negative truncation, the fixed effect Tobit model cannot obtain a consistent and unbiased estimator. Therefore, this paper uses the panel Tobit model with random effect to analyze regional carbon emission efficiency factors. To eliminate heteroscedasticity and ensure the stability of the data, this paper logarithmically processes the original data. The constructed model is as follows:

$\operatorname{lnCE} E_{i, t}=\alpha_{i, t}+\beta_{i, t} \operatorname{lnK}_{i, t}+\varepsilon_{i, t}$

where $i$ represents different influencing factors; $t$ represents time; $\alpha_{i, t}$ and $\varepsilon_{i, t}$ denote intercept term and random disturbance term, respectively; and $\beta_{\mathrm{i}, \mathrm{t}}$ represents the coefficient of each variable.

\section{Calculation model of coupling coordination degree}

The concept of a coupling degree originally comes from engineering physics. It describes the interaction and influence degree between two or more systems or factor motion modes. It is often used in economics to judge whether the development of variables is orderly (Luo et al. 2021). Since the value of coupling degree cannot accurately reflect the degree of coordinated action between variables, coupling coordination degree is based on the concept of coupling degree, which can effectively describe the influence degree and coordinated development level of multiple systems or multiple elements, which not only reflects the degree of correlation between systems but also reflects the degree of coordination between systems ( $\mathrm{Li}$ et al. 2021). To better formulate targeted policy suggestions for the nine YRB provinces on improving carbon emission efficiency, this paper constructs a coupling and coordination model of carbon emission efficiency, urbanization, and industrialization. The specific model construction steps are as follows:

(1) Establish the coupling model of carbon emission efficiency-urbanization-industrialization degree and calculate the coupling degree:

$$
C F=\sqrt[3]{\frac{C_{1} C_{2} C_{3}}{\left(C_{1}+C_{2}+C_{3}\right) / 3}}
$$

where $C F$ represents the coupling degree and $C_{1}, C_{2}$, and $C_{3}$, respectively, indicate each province's carbon emission efficiency, urbanization, and industrialization degree.
(2) To better reflect the coordinated development level of carbon emission efficiency, urbanization, and industrialization of each province, a coupling coordination degree model is constructed based on the coupling degree model. The specific model construction is as follows:

$T=\alpha C_{1}+\beta C_{2}+\gamma C_{3}$

$$
D=\sqrt{C F \times T}
$$

where $T$ represents the coordination index of carbon emission efficiency urbanization industrialization degree of each province; $\alpha, \beta$, and $\gamma$, respectively, represent the system weights of carbon emission efficiency, urbanization, and industrialization. Referring to previous studies (Guan and Xu 2014), this paper defines $\alpha, \beta, \gamma$ is $1 / 3$. Based on the existing research results (Li et al. 2019), the coupling coordination degree is divided into the following five types: barely coupling coordination (0.40 0.49), primary coupling coordination (0.5 0.59), intermediate coupling coordination (0.6 0.69), good coupling coordination (0.7 0.79), and high-quality coupling coordination $(0.8 \sim 1.00)$.

\section{Data sources}

The fossil fuels and related coefficients used to calculate carbon emissions in this paper are shown in Table 1, the relevant input-output indicators of carbon emission efficiency are shown in Table 2, and the indicators selected in the influencing factors analysis of carbon emissions efficiency are from China Statistical Yearbook (2006-2020), China Energy Statistical Yearbook (2006-2020), and IPCC (2014).

\section{Measurement of the carbon emission}

The calculation formula of regional carbon emission is as follows:

$C E_{j}=\frac{44}{12} \sum_{i=1}^{21} Q E_{i j} \times C V_{i} \times C C_{i} \times C E F_{i} \times O R_{i}$

where $\mathrm{CE}_{\mathrm{j}}$ denotes carbon emissions from fossil fuel consumption in region $\mathrm{j}$ and $Q E_{j}$ denotes the energy consumption of the fuel $i$ in region $\mathrm{j} . C V_{i}$ represents the calorific value of the $i$ th fossil fuel; $C C_{i}$ represents the carbon content; $C E F_{i}$ represents the carbon emission factor of the $i$ th fossil fuel; $O R_{i}$ represents the oxidation rate of the $i$ th fossil fuel. The correlation coefficient of relevant fossil fuels is shown in Table 1. 
Table 1 The correlation coefficient of relevant fossil fuels

\begin{tabular}{|c|c|c|c|c|}
\hline Energy type & $\begin{array}{l}\text { Calorific value }(\mathrm{KJ} / \\
\left.\mathrm{kg}, 10^{4} \mathrm{~m}^{3}\right)\end{array}$ & Carbon content (tc/TJ) & Carbon emission factors $\left(\mathrm{kgCO}_{2} / \mathrm{kg} \mathrm{m}^{3}\right)$ & Oxidation rate \\
\hline Raw coal & 20908 & 26.37 & & 0.93 \\
\hline Cleaned coal & 26344 & 25.41 & & 0.93 \\
\hline Other washed coal & 8363 & 25.41 & & 0.93 \\
\hline Briquettes & 20908 & 33.56 & & 0.93 \\
\hline Coke & 28435 & 29.42 & & 0.93 \\
\hline Coke oven gas & 17354 & 13.58 & & 0.99 \\
\hline Other gas & 5227 & 13.58 & & 0.99 \\
\hline Other coking products & 28435 & 29.42 & & 0.93 \\
\hline Crude oil & 41816 & 20.08 & & 0.98 \\
\hline Gasoline & 43070 & 2.93 & & 0.98 \\
\hline Kerosene & 43070 & 19.6 & & 0.98 \\
\hline Diesel oil & 42652 & 20.2 & & 0.98 \\
\hline Fuel oil & 41816 & 21.1 & & 0.98 \\
\hline Liquefied petroleum gas & 50179 & 17.2 & & 0.98 \\
\hline Refinery gas & 45998 & 3.04 & & 0.99 \\
\hline Other petroleum products & 41816 & 3.01 & & 0.98 \\
\hline Natural gas & 38931 & 15.32 & & 0.99 \\
\hline Gangue & 5234 & 25.77 & & 0.93 \\
\hline Blast furnace gas & 3768 & 70.8 & & 0.99 \\
\hline Converter gas & 5227 & 49.6 & & 0.99 \\
\hline Liquified natural gas & 51498 & 17.2 & & 0.98 \\
\hline
\end{tabular}

Data resource: National Bureau of Statistics of China (NBSC) (2015) and Shen et al. (2018)

Table 2 The description of the input-output indicators

\begin{tabular}{lll}
\hline Factors & Indexes & Data and description \\
\hline Input factors & Capital stock & Expressed in capital stock, calculated at constant prices in 2005, unit: 100 million yuan \\
& Labor & Expressed by the number of the urban employed population, unit:10 thousand people \\
& Energy consumption & Expressed by the consumption of main end energy varieties, unit: million tons \\
Expected output & Economic output & Expressed by regional GDP, calculated at constant prices in 2005, unit:100 million yuan \\
Unexpected output & Carbon emissions & Expressed as the amount of carbon dioxide produced by end energy consumption, unit: million tons \\
\hline
\end{tabular}

\section{Selection of input and output indicators}

Refer to previous studies on the calculation of carbon emission efficiency. This paper selects capital stock, the labor force (urban employees), and energy consumption as input factors, real GDP as the expected output, and carbon emission as unexpected output (Table 2). Among them, the capital stock is calculated according to the research of $\mathrm{Li}$ (2019) and Zhang et al. (2004). And the actual GDP is calculated based on 2005. The formula is as follows:

$\mathrm{RDK}_{\mathrm{it}}=\left(1-\delta_{\mathrm{i}}\right) \mathrm{RDK}_{\mathrm{i}, \mathrm{t}-1}+\mathrm{E}_{\mathrm{it}}$
$\mathrm{RDK}_{\mathrm{i} 0}=\frac{\mathrm{E}_{\mathrm{i} 1}}{\rho_{\mathrm{i}}+\delta_{\mathrm{i}}}$

where $\mathrm{RDK}_{\mathrm{it}}$, and $\mathrm{RDK}_{\mathrm{i}, \mathrm{t}-1}$, respectively, represent the capital stock in $t$ and $t-1$ periods; $\mathrm{E}_{\mathrm{it}}$ denotes the total investment in fixed assets after adjustment in period $t ; \mathrm{RDK}_{\mathrm{i} 0}$ indicates the initial capital stock; $\delta_{\mathrm{i}}$ represents the asset depreciation rate. In this paper, the value of $\delta_{\mathrm{i}}$ is $9.6 \%$; $\rho_{\mathrm{i}}$ denotes the average annual growth rate of investment with a constant price. In this paper, the average geometric method is used to obtain $\rho$ i. 


\section{Analysis of empirical results}

\section{Results and spatial evolution characteristics of carbon emission efficiency in the YRB}

\section{Measurement of the carbon emission efficiency}

The SBM-DDF model based on unexpected output is used to calculate the carbon emission efficiency of nine provinces in the YRB region from 2005 to 2019. The calculation results are shown in Table 3 . The average values of each year and province are solved, and the temporal and spatial evolution characteristics of carbon emission efficiency in the YRB region are analyzed.

Table 3 can directly reflect the change of carbon emission efficiency value in the YRB region from 2005 to 2019. Overall, the carbon emission efficiency values of different provinces and different years vary greatly. In terms of time series (Figure 3), the carbon emission efficiency of the YRB region shows a fluctuating upward trend. The average carbon emission efficiency increased from 0.456 in 2005 to 0.515 in 2019 , increasing by $12.94 \%$. In 2013 , the carbon emission efficiency increased the most, with $21.90 \%$, closely related to the construction of the national carbon market.

From the perspective of each province (Figure 4), the carbon emission efficiency of different provinces varies greatly. During the study period from 2005 to 2019, the carbon emission efficiency of Shaanxi is significantly higher than that of other regions, with an average of 1.148. The second is Inner Mongolia, with an average carbon emission efficiency of 0.622 . Since 2013, the carbon emission efficiency of Inner Mongolia has been greater than 1. The carbon emission efficiency of Ningxia, Qinghai, Shanxi, and Gansu provinces is generally low, and the annual change is relatively small. The carbon emission efficiency value of the four provinces fluctuates between $0.2-0.4$ in most years, and the carbon emission efficiency value is relatively low. Therefore, it is also the focus of carbon emission reduction in the YRB.

\section{Spatial evolution characteristics of carbon emission efficiency in the YRB}

To more intuitively reflect the spatial difference of carbon emission efficiency of YRB, GIS visual analysis is adopted in this paper, as shown in Figure 5. It can be seen that the carbon emission efficiency of nine provinces in the YRB varies significantly during the study period. Among them, the carbon emission efficiency of Shaanxi in the middle of the Yellow River basin is considerably higher than that of other regions. This province is rich in coal resources due to geological and historical reasons. The continuous optimization of coal and carbon production structure has gradually realized the clean and efficient utilization of coal resources. Therefore, the province's carbon emission efficiency continues to improve. Followed by Inner Mongolia, the province's carbon emission efficiency was significantly enhanced in 2013. The carbon emission efficiency value is greater than 1, which is also inseparable from the region's clean utilization of coal resources. Among the rest, the carbon emission efficiency values of Shandong, Henan,

Table 3 The carbon emission efficiency of the YRB in 2005-2019

\begin{tabular}{lllllllllll}
\hline & Shanxi & Inner Mongolia & Shandong & Henan & Sichuan & Shaanxi & Gansu & Qinghai & Ningxia & Average \\
\hline 2005 & 0.301 & 0.285 & 0.433 & 0.516 & 0.519 & 0.384 & 1.033 & 0.388 & 0.243 & 0.456 \\
2006 & 0.292 & 0.3 & 0.436 & 0.493 & 0.507 & 0.374 & 0.401 & 0.338 & 0.239 & 0.376 \\
2007 & 0.29 & 0.311 & 0.432 & 0.472 & 0.485 & 0.424 & 0.29 & 0.267 & 0.241 & 0.357 \\
2008 & 0.284 & 0.323 & 0.431 & 0.469 & 0.458 & 1.005 & 0.258 & 0.236 & 0.245 & 0.412 \\
2009 & 0.267 & 0.341 & 0.441 & 0.469 & 0.452 & 1.105 & 0.252 & 0.224 & 0.246 & 0.422 \\
2010 & 0.258 & 0.348 & 0.425 & 0.455 & 0.454 & 1.225 & 0.241 & 0.221 & 0.241 & 0.430 \\
2011 & 0.257 & 0.354 & 0.426 & 0.452 & 0.49 & 1.354 & 0.245 & 0.208 & 0.237 \\
2012 & 0.247 & 0.362 & 0.417 & 0.468 & 0.482 & 1.431 & 0.241 & 0.2 & 0.222 & 0.447 \\
2013 & 0.265 & 1.024 & 0.478 & 0.508 & 0.5 & 1.453 & 0.261 & 0.231 & 0.236 & 0.551 \\
2014 & 0.256 & 1.046 & 0.466 & 0.498 & 0.5 & 1.459 & 0.254 & 0.237 & 0.229 & 0.549 \\
2015 & 0.242 & 1.046 & 0.471 & 0.494 & 0.511 & 1.449 & 0.258 & 0.242 & 0.219 & 0.548 \\
2016 & 0.233 & 1.042 & 0.471 & 0.491 & 0.519 & 1.429 & 0.261 & 0.229 & 0.218 & 0.544 \\
2017 & 0.234 & 1.042 & 0.483 & 0.517 & 0.528 & 1.4 & 0.253 & 0.236 & 0.209 & 0.545 \\
2018 & 0.236 & 1.038 & 0.612 & 0.561 & 0.548 & 1.375 & 0.252 & 0.237 & 0.212 & 0.563 \\
2019 & 0.251 & 0.471 & 0.602 & 0.638 & 0.57 & 1.36 & 0.268 & 0.248 & 0.223 & 0.515 \\
Average & 0.261 & 0.622 & 0.468 & 0.500 & 0.502 & 1.148 & 0.318 & 0.249 & 0.231 & \\
\hline
\end{tabular}


Fig. 3 The carbon emission efficiency of provincial differences in YRB
Fig. 4 The carbon emission efficiency of annual changes in YRB

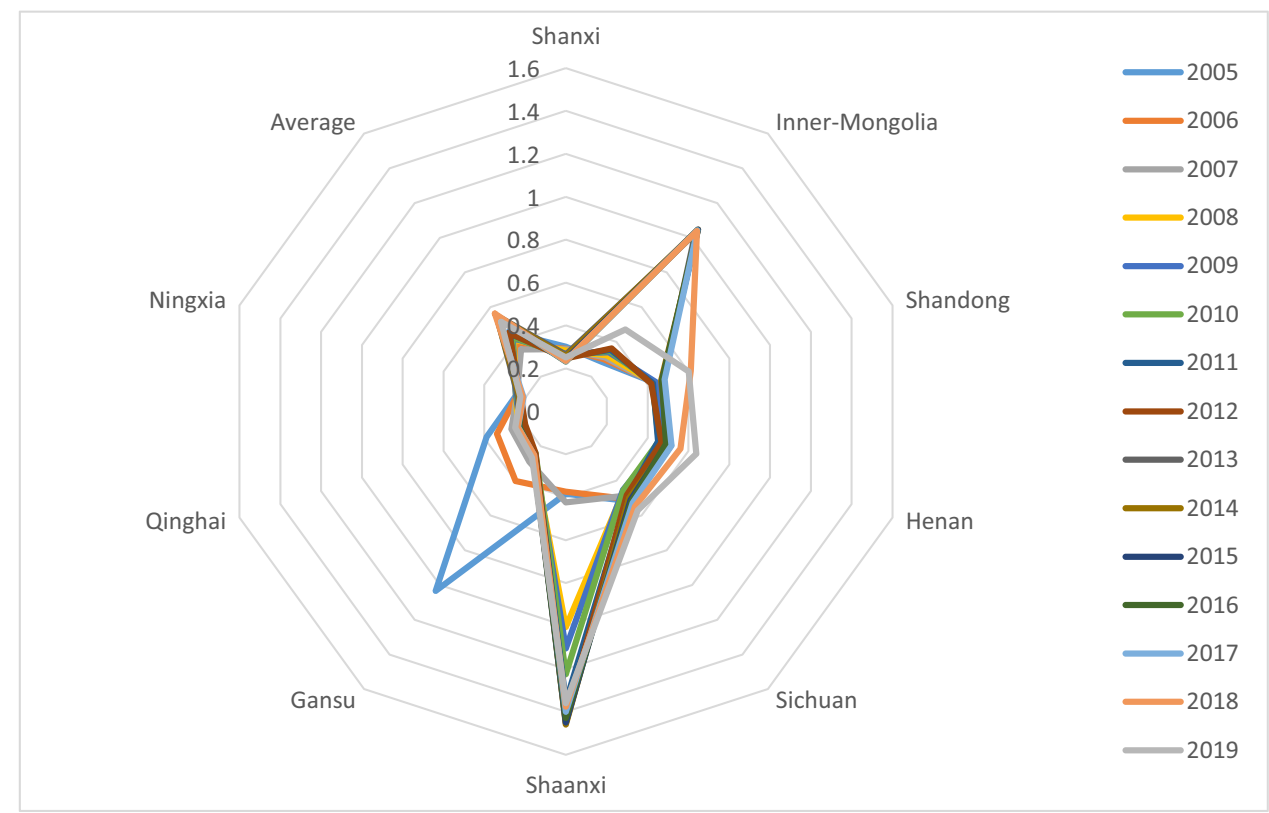

and Sichuan are at a medium level, with a large room for the rise. The carbon emission efficiency of the other five provinces is relatively low, limiting the improvement of the overall carbon emission efficiency of the YRB to a great extent. From the time section, although the carbon emission efficiency value shows an inevitable fluctuation over time, on the whole, the carbon emission efficiency value of most provinces shows an upward trend in varying degrees.

\section{Dynamic analysis results of carbon emission efficiency}

Based on the analysis of the static characteristics of carbon emission efficiency in the YRB by the SBM-DDF model considering the unexpected output in the Methodology section, this paper further analyzes the dynamic change characteristics of carbon emission efficiency in the YRB by using the ML index, as shown in Table 4. 


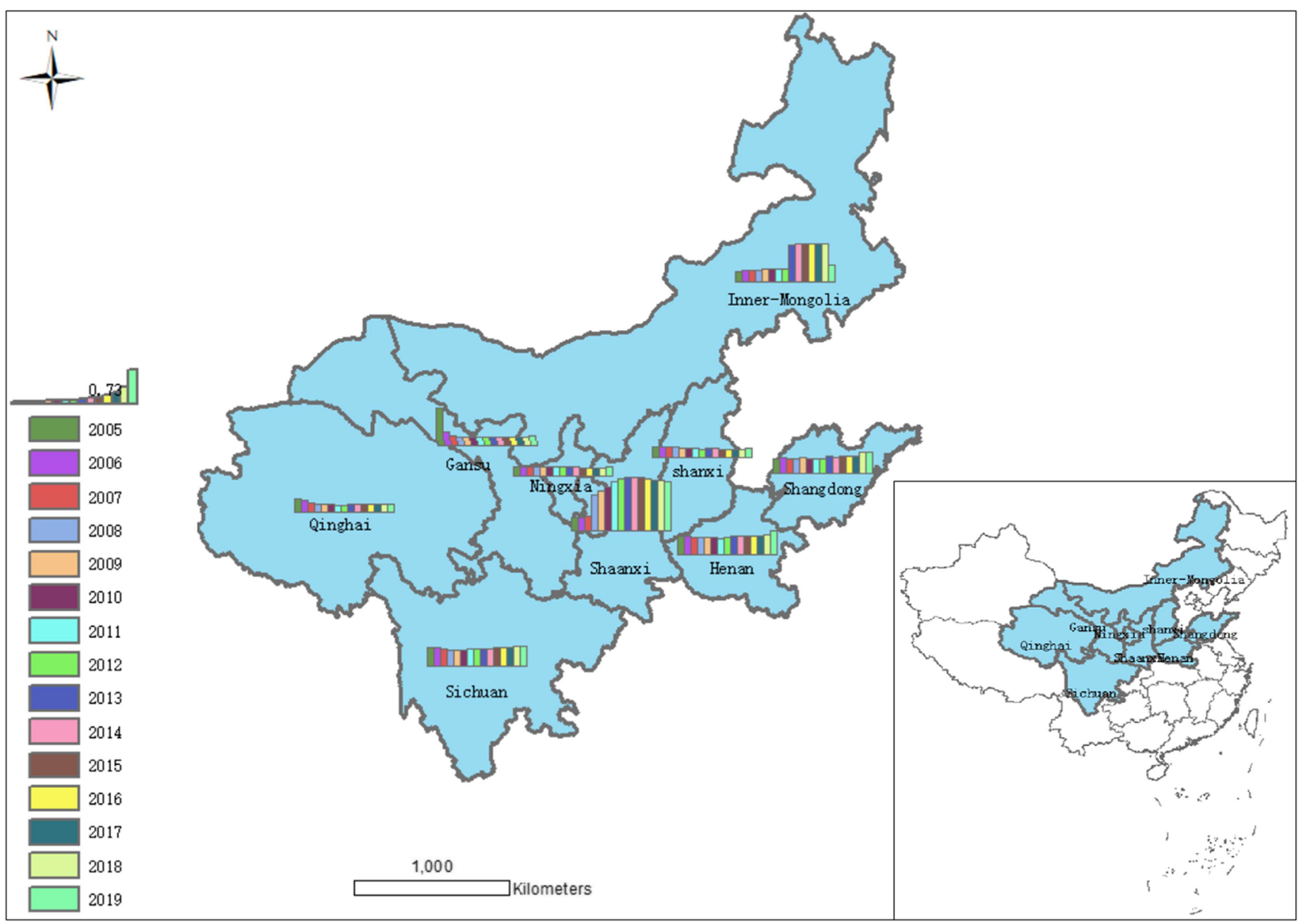

Fig. 5 Spatiotemporal change of carbon emission efficiency in the YRB

From the perspective of time series, among the nine provinces of YRB, only the overall ML index of Shandong and Gansu showed a downward trend of volatility, which decreased from 1.06 and 1.05 in 2005 to 1.04 and 1.01 in 2019. The decomposition value of the ML index shows that the decline of the TPC index is the main reason for the decrease of the ML index in Shandong. The drop of ML index in Gansu is mainly due to the decline of the TEC index from 1.00 in 2005 to 0.94 in 2019, with a decline rate of $6 \%$. The ML index of Qinghai and Ningxia has the most significant increase, with $11.85 \%$ and $11.56 \%$, respectively. It can be seen from the decomposition value of ML that the stable rise of TEC is the main reason for the increase of the ML index in these two provinces. Secondly, Shanxi and Inner Mongolia have a higher growth rate, rising from 1.00 and 0.99 in 2005 to 1.07 and. 07 in 2019, with an increase of 7\% and $7.61 \%$, respectively. In the other three provinces, Henan, Sichuan, and Shaanxi, the growth rate was between 2 and $4 \%$. The increase of TPC is the common reason for the rise of the ML index in these three provinces, which shows that the technological progress of these three provinces is fast.
From the average decomposition results, the average TEC of Shanxi and Gansu is only 0.98 , which is significantly lower than the TPC index of the two provinces, which is the fundamental reason for hindering the improvement of the ML index. This shows that the two provinces should improve technical efficiency in future development by enhancing the pure technical efficiency or expanding the technical scale to improve overall efficiency. The average TPC index of Qinghai and Ningxia is 0.99 , indicating that the two provinces should pay more attention to technological progress, introduce high and new technologies from developed areas to accelerate the development of low-carbon technologies, pay attention to energy transformation, and encourage cleaner production.

\section{Analysis on influencing factors of carbon emission efficiency}

To further explore the reasons for the significant difference in carbon emission efficiency among nine provinces in the YRB, the Tobit model is introduced to analyze the 


\begin{tabular}{|c|c|}
\hline$\sum^{\tilde{\Xi}}$ & 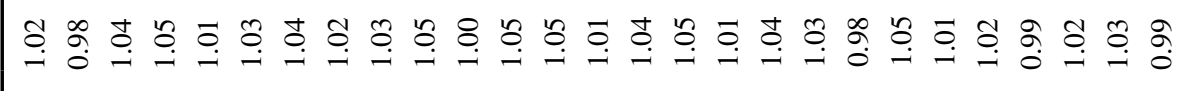 \\
\hline 㹧 & 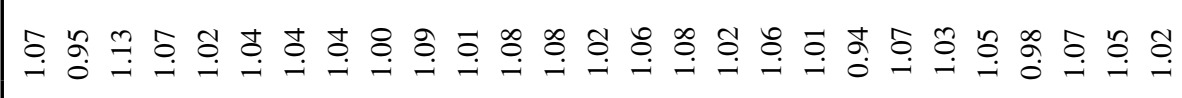 \\
\hline 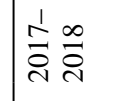 & 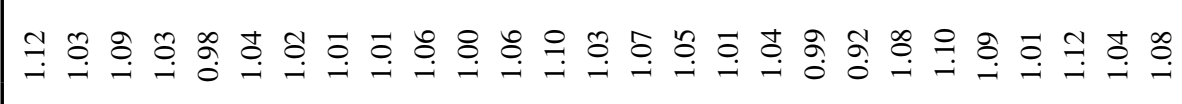 \\
\hline 훌 & 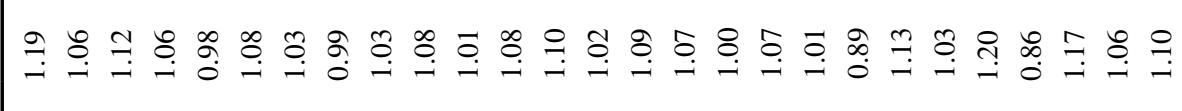 \\
\hline ำ & 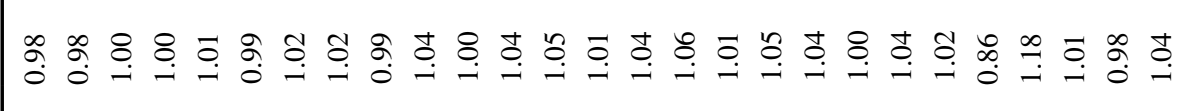 \\
\hline 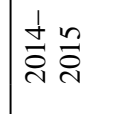 & 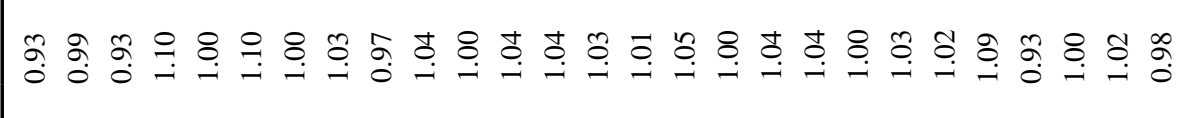 \\
\hline 产 & ఠ̊ \\
\hline 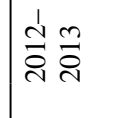 & 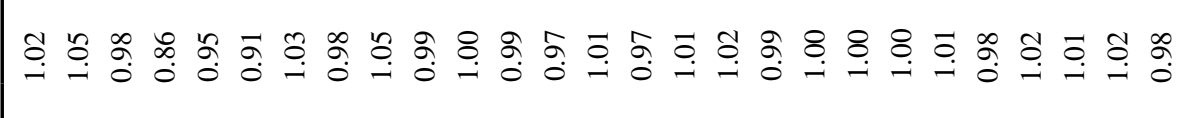 \\
\hline 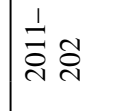 & 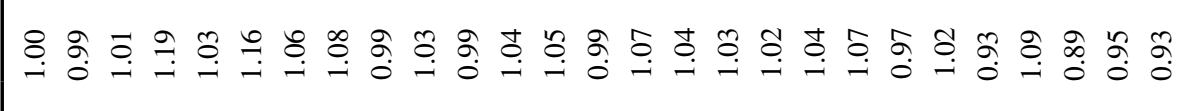 \\
\hline 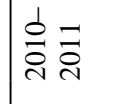 & 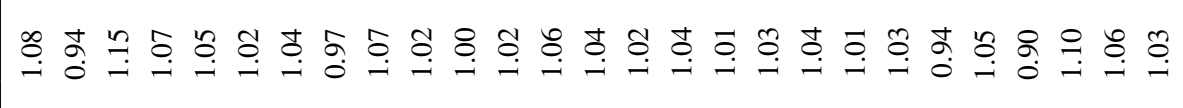 \\
\hline 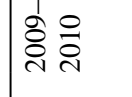 & o \\
\hline 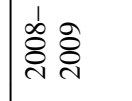 & 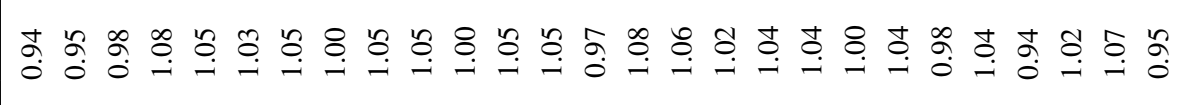 \\
\hline$\overbrace{\substack{1 \\
0}}^{\infty}$ & 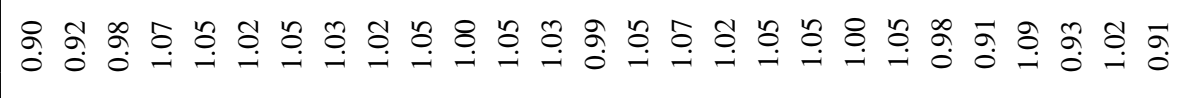 \\
\hline$\overbrace{\substack{0 \\
\hdashline}}^{0}$ & \& \& \& \& \\
\hline 皇 & 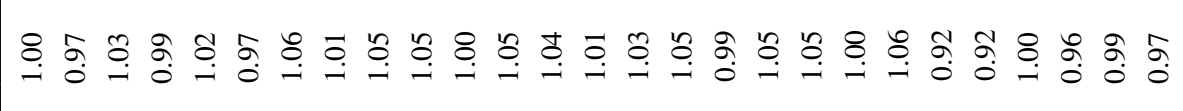 \\
\hline 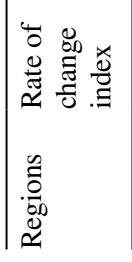 & 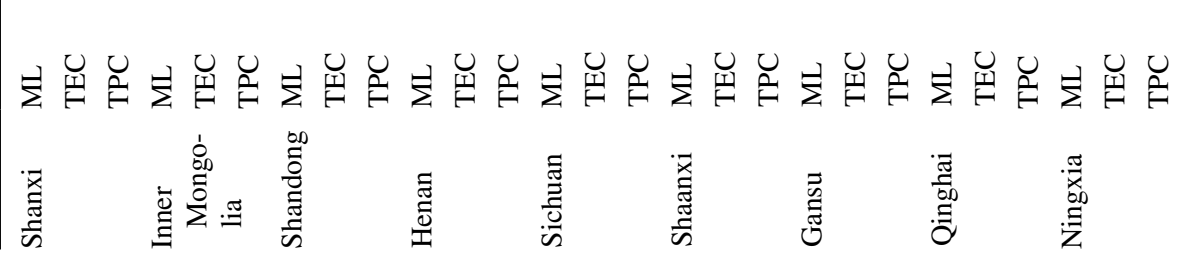 \\
\hline
\end{tabular}


influencing factors of carbon emission efficiency in the YRB. According to previous studies, this paper mainly selects 15 indicators such as population, energy consumption, per capita electricity consumption, per capita GDP, trade degree, urbanization rate, and industrial structure, for analysis. The model results are shown in Table 5.

It can be seen from Table 6 that GDP per capita $\left(K_{4}\right)$, the proportion of industrial output value $\left(K_{5}\right)$, proportion of tertiary industry $\left(K_{6}\right)$, import and export volume $\left(K_{10}\right)$, and forest coverage $\left(K_{14}\right)$ have a significant positive impact on the carbon emission efficiency of the YRB. In the positive impact relationship, the elastic coefficient of $K_{6}$ is the largest, which is 3.732 and has passed the significance test at the $1 \%$ level. It shows that for every $1 \%$ increase in the proportion of the tertiary industry, the carbon emission efficiency increases by $3.732 \%$. Regulating the output value of the tertiary sector is a meaningful way to improve the carbon emission efficiency of the YRB. The elasticity coefficient of $K_{4}$ is 2.738 , which has passed the significance test of $1 \%$ level. When other conditions remain unchanged, the carbon emission efficiency increases by $2.738 \%$ for every $1 \%$ increase in per capita GDP. It shows that with the improvement of economic development level, people's environmental requirements are also relatively improved. The government will invest more funds in ecological governance and low-carbon technology, so the carbon emission efficiency has been dramatically improved. The elastic coefficients of $K_{10}$ and $K_{14}$ are 0.200 and 0.447 , respectively, which have passed the significance test of $5 \%$ and $1 \%$, respectively; when other conditions remain unchanged, the carbon emission efficiency increases by $0.2 \%$ and $0.447 \%$ for every $1 \%$ increase in import and export volume or forest coverage.
Electricity consumption per capita $\left(K_{3}\right)$, technical turnover $\left(K_{9}\right)$, urbanization rate $\left(K_{12}\right)$, and forest volume $\left(K_{15}\right)$ have a significant negative impact on the carbon emission efficiency of the YRB. Among them, the elastic coefficient of $K_{12}$ is the largest, which is -4.338 and has passed the significance test of $1 \%$ level, indicating that when other conditions remain unchanged, the regional carbon emission efficiency of the YRB will decrease by $4.338 \%$ for every $1 \%$ increase in urbanization rate. Therefore, regulating the growth rate of population urbanization is the key to improving carbon emission efficiency in this region. The second largest elastic coefficient is the $K_{3}$, with an elasticity coefficient of -1.072 , indicating that the carbon emission efficiency decreases by $1.072 \%$ when the per capita power consumption increases by $1 \%$. The elastic coefficients of $K_{9}$ and $K_{15}$ are -0.124 and -0.187 , respectively, and both passed the significance test at the $1 \%$ level.

The rest of the population $\left(K_{1}\right)$, energy consumption $\left(K_{2}\right)$, the proportion of industrial output value $\left(K_{5}\right)$, proportion of thermal power generation $\left(K_{7}\right)$, authorized amount of invention patents $\left(K_{8}\right)$, the proportion of coal consumption $\left(K_{11}\right)$, and environmental protection expenditure $\left(K_{13}\right)$ have not passed the significance test at the 5\% level. Therefore, the changes in the above indicators will not significantly impact the carbon emission efficiency of the YRB.

\section{Results of coupling coordination degree model}

According to the analysis results of the main influencing factors affecting the carbon emission efficiency of the YRB, it can be concluded that urbanization and industrial structures are the leading negative and positive indicators

Table 5 Results of spatial lag panel Tobit

\begin{tabular}{lllllll}
\hline $\begin{array}{l}\text { Explanatory } \\
\text { variable }\end{array}$ & Indicator & Coefficient & Standard error & $z$ value & $p$ value & $95 \%$ conf. interval \\
\hline$K_{1}$ & Population & -0.399 & 0.272 & -1.465 & 0.143 & $-0.932 \sim 0.135$ \\
$K_{2}$ & Energy consumption & 0.327 & 0.203 & 1.616 & 0.106 & $-0.070 \sim 0.725$ \\
$K_{3}$ & Electricity consumption per capita & -1.072 & 0.223 & -4.811 & 0.000 & $-1.509 \sim-0.635$ \\
$K_{4}$ & GDP per capita & 2.738 & 0.366 & 7.481 & 0.000 & $2.021 \sim 3.455$ \\
$K_{5}$ & Proportion of industrial output value & 0.682 & 0.365 & 1.867 & 0.062 & $-0.034 \sim 1.397$ \\
$K_{6}$ & Proportion of tertiary industry & 3.732 & 0.762 & 4.896 & 0.000 & $2.238 \sim 5.226$ \\
$K_{7}$ & Proportion of thermal power generation & -0.364 & 0.217 & -1.678 & 0.093 & $-0.788 \sim 0.061$ \\
$K_{8}$ & Authorized amount of invention patents & -0.150 & 0.092 & -1.624 & 0.104 & $-0.331 \sim 0.031$ \\
$K_{9}$ & Technical turnover & -0.124 & 0.037 & -3.310 & 0.001 & $-0.197 \sim-0.051$ \\
$K_{10}$ & Import and export volume & 0.200 & 0.087 & 2.302 & 0.021 & $0.030 \sim 0.370$ \\
$K_{11}$ & Proportion of coal consumption & 0.162 & 0.296 & 0.549 & 0.583 & $-0.418 \sim 0.743$ \\
$K_{12}$ & Urbanization rate & -4.338 & 0.725 & -5.984 & 0.000 & $-5.758 \sim-2.917$ \\
$K_{13}$ & Environmental protection expenditure & 0.007 & 0.075 & 0.097 & 0.923 & $-0.139 \sim 0.154$ \\
$K_{14}$ & Forest coverage & 0.447 & 0.135 & 3.310 & 0.001 & $0.182 \sim 0.712$ \\
$K_{15}$ & Forest volume & -0.187 & 0.060 & -3.144 & 0.002 & $-0.304 \sim-0.071$ \\
\hline
\end{tabular}


Table 6 Coupling coordination degree and coupling state of nine provinces in the YRB

\begin{tabular}{|c|c|c|c|c|c|c|c|c|c|}
\hline & Shanxi & $\begin{array}{l}\text { Inner Mon- } \\
\text { golia }\end{array}$ & Shandong & Henan & Sichuan & Shaanxi & Gansu & Qinghai & Ningxia \\
\hline 2005 & 0.446 & 0.55 & 0.448 & 0.244 & 0.418 & 0.519 & 0.398 & 0.591 & 0.468 \\
\hline 2006 & 0.429 & 0.571 & 0.457 & 0.247 & 0.434 & 0.542 & 0.402 & 0.564 & 0.464 \\
\hline 2007 & 0.432 & 0.589 & 0.466 & 0.284 & 0.468 & 0.585 & 0.392 & 0.515 & 0.469 \\
\hline 2008 & 0.452 & 0.608 & 0.492 & 0.272 & 0.48 & 0.738 & 0.399 & 0.479 & 0.479 \\
\hline 2009 & 0.47 & 0.63 & 0.492 & 0.341 & 0.494 & 0.779 & 0.414 & 0.465 & 0.484 \\
\hline 2010 & 0.444 & 0.644 & 0.491 & 0.325 & 0.518 & 0.809 & 0.413 & 0.469 & 0.482 \\
\hline 2011 & 0.422 & 0.652 & 0.505 & 0.349 & 0.538 & 0.835 & 0.426 & 0.433 & 0.485 \\
\hline 2012 & 0.41 & 0.66 & 0.511 & 0.376 & 0.535 & 0.863 & 0.434 & 0.405 & 0.459 \\
\hline 2013 & 0.433 & 0.861 & 0.544 & 0.414 & 0.544 & 0.878 & 0.476 & 0.501 & 0.491 \\
\hline 2014 & 0.45 & 0.871 & 0.552 & 0.439 & 0.548 & 0.886 & 0.484 & 0.519 & 0.484 \\
\hline 2015 & 0.475 & 0.879 & 0.575 & 0.484 & 0.564 & 0.906 & 0.502 & 0.53 & 0.471 \\
\hline 2016 & 0.475 & 0.887 & 0.596 & 0.516 & 0.568 & 0.92 & 0.517 & 0.512 & 0.475 \\
\hline 2017 & 0.486 & 0.901 & 0.619 & 0.548 & 0.573 & 0.931 & 0.523 & 0.533 & 0.456 \\
\hline 2018 & 0.501 & 0.907 & 0.677 & 0.582 & 0.595 & 0.939 & 0.533 & 0.54 & 0.469 \\
\hline 2019 & 0.528 & 0.758 & 0.693 & 0.615 & 0.618 & 0.949 & 0.56 & 0.562 & 0.504 \\
\hline Average & 0.457 & 0.731 & 0.541 & 0.402 & 0.526 & 0.805 & 0.458 & 0.508 & 0.476 \\
\hline $\begin{array}{l}\text { Coupling } \\
\text { coordina- } \\
\text { tion state }\end{array}$ & $\begin{array}{l}\text { Barely } \\
\text { coupling } \\
\text { coordina- } \\
\text { tion }\end{array}$ & $\begin{array}{l}\text { Good } \\
\text { coupling } \\
\text { coordina- } \\
\text { tion }\end{array}$ & $\begin{array}{l}\text { Primary } \\
\text { coupling } \\
\text { coordina- } \\
\text { tion }\end{array}$ & $\begin{array}{l}\text { Barely } \\
\text { coupling } \\
\text { coordina- } \\
\text { tion }\end{array}$ & $\begin{array}{l}\text { Primary } \\
\text { coupling } \\
\text { coordina- } \\
\text { tion }\end{array}$ & $\begin{array}{l}\text { High-quality } \\
\text { coupling } \\
\text { coordina- } \\
\text { tion }\end{array}$ & $\begin{array}{l}\text { Barely } \\
\text { coupling } \\
\text { coordina- } \\
\text { tion }\end{array}$ & $\begin{array}{l}\text { Primary } \\
\text { coupling } \\
\text { coordina- } \\
\text { tion }\end{array}$ & $\begin{array}{l}\text { Barely } \\
\text { cou- } \\
\text { pling } \\
\text { coordi- } \\
\text { nation }\end{array}$ \\
\hline
\end{tabular}

affecting the region's carbon emission efficiency, respectively. How to formulate targeted policy suggestions to improve carbon emission efficiency for different provinces needs to explore further the coordinated development degree and coupling state among carbon emission efficiency, urbanization, and industrial structure in other provinces. Therefore, this paper introduces the coupling coordination degree model to calculate the development status of each province to formulate corresponding emission reduction suggestions for different provinces. The results are shown in Table 6.

From the calculation results of provincial coupling coordination degree, the spatial distribution of coupling coordination degree of urbanization, industrialization level, and carbon emission efficiency in the YRB is consistent with carbon emission efficiency. The high-value areas of carbon emission efficiency (Inner Mongolia and Shaanxi) are also in the high-value areas of coupling coordination degree. Due to the economic development brought by the improvement of urbanization level and the increase of the output value of the tertiary industry, the carbon emission efficiency is improved. The provinces have low-carbon emission efficiency (Shanxi, Henan, Gansu, and Ningxia); their coupling and coordinated dispatching are also low. The carbon emission efficiency, urbanization, and proportion of tertiary industry of these provinces show a low level of coordinated development, and their economic status is also common. The industrial structure needs to be optimized. More control should be given in the process of accelerating urbanization.

In terms of time series, only Qinghai among the nine provinces in the YRB shows a fluctuating downward trend, from 0.591 in 2005 to 0.562 in 2019 . The province with the highest coupling coordination is Shaanxi, with an average of 0.805 , followed by Inner Mongolia, with a coupling coordination degree of 0.731 . The coupling and coordination degree of these two provinces are significantly higher than that of the other seven provinces, which shows that these two provinces' carbon emission efficiency, urbanization, and industrial structure have reached a certain degree of coupling and coordination. In the future carbon emission reduction work, we should pay more attention to other aspects such as per capita GDP, industrialization level, and per capita power consumption level to improve the carbon emission efficiency of the provinces.

The average coupling coordination degree of Shanxi, Henan, Gansu, and Ningxia are 0.457, 0.402, 0.458, and 0.476 , respectively, indicating that the coupling coordination degree between carbon emission efficiency and urbanization and industrial structure of these four provinces is low. To improve the carbon emission efficiency of these provinces, 
we should encourage the development of tertiary industry in this region and adequately control the urbanization progress of this region. The coupling coordination degree of the other three provinces, Shandong, Sichuan, and Qinghai, ranges from 0.5 to 0.55 . However, in terms of time, the coupling coordination degree of Shandong and Sichuan increased significantly in 2013 and 2011, respectively, indicating that the two regions began to pay attention to the control of urbanization and the upgrading of industrial structure in the process of development. Therefore, management in this area should be further strengthened in future growth.

\section{Conclusions and policy recommendations}

\section{Conclusions}

Based on the existing research on carbon emission efficiency, this paper first constructs the SBM-DDF model based on unexpected output, which differs from previous studies on carbon emission efficiency. Then, combined with the ML index, the carbon emission efficiency of YRB is dynamically decomposed, and the main reasons affecting the rise or decline of the ML index in different provinces of YRB are identified. Finally, combined with the Tobit model, this paper explores the main factors affecting the carbon emission efficiency of YRB. And combined with the coupling coordination degree model, this paper calculates the coupling coordination between the carbon emission efficiency of nine provinces in the YRB region and the two main influencing factors of urbanization and industrial structure and formulates the specific emission reduction measures nine provinces in YRB. The research conclusions are mainly in the following three aspects:

(1) On the whole, the average carbon emission efficiency of the YRB showed a fluctuating upward trend during the study period, increasing by nearly 13 percentage points from 0.456 in 2005 to 0.515 in 2019 . The contribution rate of carbon emission in the YRB region is much higher than the economic contribution rate of the region, belonging to the high-value area of carbon emission. From the perspective of each province, the carbon emission efficiency values of different provinces are significantly different. Shaanxi has the highest average emission efficiency, with an efficiency value of 1.148. The lowest is Ningxia, which is only 0.231 . There is a significant gap in carbon emission efficiency among provinces.

(2) From the dynamic decomposition results of carbon emission efficiency, technological progress and tech- nological efficiency are the main reasons for the rise or decline of the ML index of carbon emission efficiency in different provinces. From the perspective of time, only the ML index of Shandong and Gansu shows a fluctuating downward trend. The decline of the ML index in these two provinces is caused by reducing the technological progress index and technical efficiency index, respectively. Henan, Sichuan, and Shaanxi are the provinces where the rise of the TPC technological progress index leads to an increase of ML index. Shanxi and Inner Mongolia are the provinces where the surge of the TEC index leads to the rise of the ML index. From the mean value, the TEC index of Shanxi and Gansu is 0.98, and the TPC index of Qinghai and Ningxia is 0.99 . Their index decomposition results are less than 1 . Therefore, these factors seriously affect the improvement of the ML index in the above provinces.

(3) Through YRB regional carbon emission efficiency analysis, it is concluded that the industrial structure and urbanization levels are the leading positive and negative indicators affecting the regional carbon emission efficiency. Combined with the calculation results of the coupling coordination model between carbon emission efficiency and industrial structure and urbanization, we found that the coupling coordination degree corresponding to high-value areas of carbon emission efficiency (such as Shaanxi and Inner Mongolia) is also high, while the coupling coordination degree corresponding to low-value regions in carbon emission efficiency (Shanxi, Henan, Gansu, and Ningxia, etc.) is also relatively low.

\section{Policy recommendations}

Based on the above research conclusions, this paper attempts to formulate targeted carbon emission reduction policy suggestions for nine provinces of YRB from three angles:

(1) The high contribution rate of energy consumption and carbon emission of YRB is mainly due to the large population density, resource endowment, different stages of economic development, and other factors in the region. Shanxi is a large coal province in China, while Shandong, Henan, and Sichuan are populous central provinces in China. Their different development characteristics and stages lead to significant differences in carbon emission efficiency. To achieve the grand goals of carbon peak in 2030 and carbon neutralization in 2060, as a high-value area of carbon emissions, the industrial structure of each province in the region should be adjusted as soon as possible. Encourage low-carbon 
emission efficiency areas (such as Ningxia) to adopt the carbon emission reduction experience of high carbon emission efficiency areas (such as Shaanxi), realize the coordinated development among the nine provinces of YRB as soon as possible, and jointly realize the transformation of low-carbon emission reduction.

(2) To improve the carbon emission efficiency of all provinces in the region as a whole, targeted guidance should be given according to the ML index decomposition results of different provinces. In the process of future economic development, areas with low TEC index, such as Shanxi and Gansu, should improve technical efficiency by improving pure technical efficiency and expanding technical scale and strictly grasp traditional energy such as coal environmental protection standards to achieve efficient transformation and transformation of new and old kinetic energy. Provinces with low TPC index such as Qinghai and Ningxia should pay more attention to technological progress, limit the entry of high energy consumption and high pollution industries, control the total energy consumption, adhere to the principle of giving priority to development, adhere to green mining and utilization, introduce high and new technologies in developed areas to accelerate the growth of low-carbon technologies, pay attention to energy transformation, and encourage cleaner production. The region as a whole should focus on promoting new energy investment and actively promoting new energy such as wind power, photovoltaic and solar energy and strive to control carbon emissions from the source. Wind power abd photovoltaic and solar energy seek to regulate carbon emissions from the start.

(3) To improve the overall carbon emission efficiency of the YRB, we should appropriately expand the development of tertiary industry and the improvement of residents' living standards in the region, control the urbanization process, and solve the supporting resettlement problems such as housing, travel, and employment of the urban migrant population. For high-value carbon emission efficiency and high-value coupling and coordination areas such as Shaanxi and Inner Mongolia, based on consolidating the initial urbanization planning and industrial structure design, we should pay more attention to the improvement of per capita living standard and per capita power consumption efficiency in the province. Provinces with low-carbon emission efficiency and coupling coordination, such as Shanxi, Henan, and Ningxia, should first strengthen the supporting design of urbanization and the upgrading of industrial structures to improve the carbon emission efficiency of the province fundamentally.

\section{Discussion}

With the proposed national strategy to ensure ecological protection and high-quality development of the RB in 2019, given this, scholars at home and abroad have studied the region from many fields, such as land use ( $\mathrm{Lu}$ et al. 2020; Chi et al. 2000; Ma and Liu 2021), agricultural water use efficiency (Wei et al. 2021), ecosystem service function (Fang et al. 2021), transportation (Zhang and Su 2020), tourism (Huang et al. 2021), and sustainable development efficiency (Khan et al. 2021). As the population and economic contribution of the YRB play an important role, and the region belongs to a high-value area of carbon emission, the improvement of carbon emission efficiency in the region is the key to achieving China's " 30.60 " carbon emission reduction targets.

The primary motivation of this study is to explore the temporal and spatial evolution characteristics of the differences in carbon emission efficiency among the nine provinces of YRB and how to improve the carbon emission efficiency of different provinces effectively. Unlike previous studies, this paper analyzes the evolution characteristics of carbon emission efficiency in the region from the static characteristics of YRB carbon emission efficiency. It dynamically analyzes the main reasons for the rise or decline of ML in different provinces combined with the ML index. At the same time, this paper calculates the coupling coordination degree based on exploring the influencing factors and influence degree of carbon emission in the region and formulates targeted policy suggestions to improve carbon emission efficiency for different provinces according to the calculation results.

\section{Differences}

Since this study is based on the previous studies (Zhang and Su 2020; Huang et al. 2021; Ma and Liu 2021; Yuan et al. 2022; Sun et al. 2021), so the previous studies are discussed firstly.

To explore the influencing factors and trends of traffic carbon emissions in the YRB, Zhang and Su (2020) calculated the traffic carbon emissions in the YRB from 1998 to 2017. They intensely studied the impact of population size, urbanization rate, per capita GDP, industrial structure, and clean energy consumption on carbon emissions in the YRB. The results show that population size and per capita GDP significantly affect carbon emission in the YRB. Although this paper calculates the main factors affecting the traffic carbon emission of YRB, it does not make a differential analysis according to the specific 
situation of each province. Huang and Wang et al. (2021) scientifically measured the decoupling effect between the economic development of tourism and its carbon emission in the YRB. Using the experimental spatial analysis method, they revealed the spatial pattern evolution characteristics of the carbon emission decoupling index in different provinces. They have proposed to formulate the low-carbon development path of tourism and the coordinated development path of the whole basin according to local conditions to jointly promote the energy conservation and emission reduction of tourism in the YRB and realize the convergence of low-carbon development clubs of tourism in different provinces and regions. Ma and Liu (2021) analyzed the temporal and spatial pattern evolution and influencing factors of land use carbon emission in the YRB through the land use, energy consumption, and relevant economic statistical data of various provinces in the YRB from 2000 to 2017. The research results show that the carbon emission of construction land increases significantly, and the carbon emission intensity per unit GDP decreases continuously. The main factors affecting carbon emissions in the YRB are land use, energy structure, and industrial structure. Different driving factors have significant differences in different provinces' impacts and times. Therefore, targeted emission reduction measures should be put forward according to the characteristics of different provinces. Yuan et al. (2022) used the multi-regional input-output model to estimate the carbon footprint of nine provinces in the YRB and the implied carbon transfer between industrial sectors in different provinces. The research results show significant differences in carbon transfer among different provinces. The implied carbon transfer in the middle-lower of the YRB is much higher than that in the upper of the YRB. Calculating the carbon transfer of three industries in different regions provides a theoretical basis and reliable data support for different provinces and initiatives in the YRB to formulate carbon emission reduction schemes. Sun et al. (2021) selected 36 cities in the YRB and divided them into four categories. They calculated the impact of different urban levels and various factors on $\mathrm{CO} 2$ emission in the YRB by using the STIRPAT model and conducted panel regression analysis on the whole Yellow River basin and four types of urban agglomerations, respectively. The results show that urbanization has a significant negative impact on carbon emission, which is consistent with the research results of this paper.

Although the existing literature has made considerable achievements in carbon emission and carbon emission efficiency, there are mainly the following two deficiencies: (1) few literatures analyze the dynamic change of carbon emission efficiency of YRB from a non-radial perspective. (2) When calculating the impact factor analysis, most studies only calculated the impact factors and impact degree at the regional level, without in-depth analysis according to the specific situation of each province.

To make up for the above shortcomings, firstly, combined with the advantages of the SBM-DDF model based on unexpected output and ML index, this paper analyzes the evolution characteristics of carbon emission efficiency of each province from static and dynamic perspectives. Secondly, through the panel Tobit model of random effect, the main positive and negative influencing factors in the corresponding YRB area are calculated. Finally, to further formulate reasonable policy suggestions for each province, this paper constructs a coupling coordination degree model based on the calculation of the main influencing factors, which provides data support and a theoretical basis for each province to improve carbon emission efficiency.

\section{Advantages}

The main advantages of this paper are as follows:

(1) By introducing the non-radial SBM-DDF model based on unexpected output, the carbon emission efficiency values of nine YRB provinces from 2005 to 2019 are calculated more accurately. This paper analyzes the temporal and spatial evolution characteristics of the carbon emission efficiency of YRB in each province from a static point of view. It decomposes it into technical efficiency index and technological progress index from a dynamic point of view with the help of the ML index. The main reasons for the rise or decline of the ML index in different provinces are obtained. Combining these two methods has higher accuracy and better effect and has a more substantial interpretation of the results.

(2) Because the calculated carbon emission efficiency values are more significant than zero and non-negative truncation characteristics, the fixed effect Tobit model cannot obtain a consistent, unbiased estimator. Therefore, the panel Tobit model with random effect is adopted to explore the main influencing factors and influence degree affecting the carbon emission efficiency of the YRB. It lays a good foundation for accurately detecting the influencing factors affecting the carbon emission efficiency of YBR.

(3) Different from previous studies, after calculating the influencing factors affecting the carbon emission efficiency of the YRB, this paper selects the leading positive and negative indicators, calculates the coupling coordination degree with the carbon emission efficiency, and obtains the coupling coordination state of each province in the region. This helps to find out how to improve carbon emission efficiency in each province 
of the YRB and provides an excellent theoretical basis and data support for realizing the regional carbon emission reduction target.

Author contribution Yuan Zhang mainly designed the structure and research methods of the paper and the full text's writing. Xiangyang $\mathrm{Xu}$ is responsible for the conceptualization and methodology, collects data, and is responsible project administration.

Availability of data and materials The datasets generated and analyzed during the current study are not publicly available but are available from the corresponding author on reasonable request.

\section{Declarations}

Ethics approval and consent to participate Not applicable.

Consent for publication Not applicable.

Conflict of interest The authors declare no competing interests.

\section{References}

Cao YR, Liu J, Yu Y, Wei G (2020) Impact of environmental regulation on green growth in China's manufacturing industry-based on the Malmquist-Luenberger index and the system GMM model. Environ Sci Pollut Res Int 27(33):41928-41945

Chang YT, Zhang N et al (2013) Environmental efficiency analysis of transportation system in China: a non-radial DEA approach. Energy Policy 58:277-283

Chi Q, Shi Zhou, Wang LJ et al (2021) Exploring on the eco-climatic effects of land use changes in the influence area of the Yellow River basin from 2000 to 2015. Land 10(6):601

Cui HL, Varatharajan Ramachandran (2021) Performance evaluation of logistics enterprises based on non-radial and non-angle network SBM model. J Intell Fuzzy Syst 40(4):6541-6553

Dong F, Zhang YQ, Zhang XY (2020) Applying a data envelopment analysis game cross-efficiency model to examining regional ecological efficiency: evidence from China. J Clean Prod 267:122031

Fang LL, Wang LC, Chen WX et al (2021) Identifying the impacts of natural and human factors on ecosystem service in the Yangtze and Yellow River basins. J Clean Prod 314:127995

Färe R, Grosskopf S, Pasurka CA (2007) Environmental production functions and environmental directional distance functions. Energy 32(7):1055-1066

Fukuyama H, Weber WL (2008) A directional slacks-based measure of technical inefficiency. Socio-Econ Plann Sci 43(4):274-287

Guan W, Xu ST (2014) Spatial patterns and coupling relations between energy efficiency and industrial structure in Liaoning Province. Acta Geogr Sin 69(04):520-530

Huang GQ, Wang ZL, Shi PF, Zhou Y (2021) Measurement and spatial heterogeneity of tourism carbon emission and its decoupling effects: a case study of the Yellow River basin in China. China Soft Sci 04:82-93

IPCC (2014) Climate change 2014: mitigation of climate change. Cambridge University Press, Cambridge
Jin FJ (2019) Coordinated promotion strategy of ecological protection and high-quality development in the Yellow River basin. Reform 11:304-310

Jiang HL (2021) Spatial-temporal differences of industrial land use efficiency and its influencing factors for China's central region: analyzed by SBM model. Environ Technol Innov 22:101489

Khan SU, Cui Y, Khan AA et al (2021) Tracking sustainable development efficiency with human-environmental system relationship: an application of DPSIR and super efficiency SBM model. Sci Total Environ 783:146959

Li B, Han SW et al (2020) Feasibility assessment of the carbon emissions peak in China's construction industry: factor decomposition and peak forecast. Sci Total Environ 70(135716):1-13

Li JB, Huang XJ, Sun SC et al (2019) Spatio-temporal coupling analysis of urban land and carbon dioxide emissions from energy consumption in the Yangtze River Delta region. Geogr Res 38(09):2188-2201

Li WJ, Wang Y, Xie SY, Cheng X (2021) Coupling coordination analysis and spatiotemporal heterogeneity between urbanization and ecosystem health in Chongqing municipality, China. Sci Total Environ 791:148311

Li WW, Wang WP, Gao HW, et al. (2020) Evaluation of regional metafrontier total factor carbon emission performance in China's construction industry: analysis based on modified non-radial directional distance function. J Clean Prod 256(C):120425

Li XJ, Xu JW, Ren X et al (2012) Man-Land relationship and development in the regions along Yellow River. Hum Geogr 27(1):7-11

Li Y (2019) Research on the measurement and spatial characteristics of China's provincial R\&D capital stock. Soft Sci 33(07):21-26+33.

Li Y, Li JW, Gong Y, Wei FQ, Huang QB (2020) CO2 emission performance evaluation of Chinese port enterprises: a modified metafrontier non-radial directional distance function approach. Transp Res Part D 89:102605

Liu F, Chen SL et al (2012) Spatial and temporal variability of water discharge in the Yellow River Basin over the past 60 years. J Geogr Sci 22(6):1013-1033

Liu HW, Yang RL, Wu DD et al (2021) Green productivity growth and competition analysis of road transportation at the provincial level employing Global Malmquist-Luenberger index approach. J Clean Prod 279(2):123677

Liu KD, Yang DG, Yang GL, Zhou ZT (2020) Assessing the regional sustainability performance in China using the global MalmquistLuenberger productivity index. Int J Energy Sect Manag 15(4). https://doi.org/10.1108/IJESM-03-2019-0023

Liu Z, Zhang H, Zhang YJ et al (2020) How does income inequality affect energy efficiency? Empirical evidence from 33 Belt and Road Initiative countries. J Clean Prod 269:122421

Luo D, Liang LW, Wang ZB et al (2021) Exploration of coupling effects in the economy-society-environment system in urban areas: case study of the Yangtze River Delta urban agglomeration. Ecol Indic 128:107858

Lu DD, Sun DQ (2019) Development and management tasks of the Yellow River basin: a preliminary understanding and suggestion. Acta Geogr Sin 74(12):2431-2436

Lu X, Qu Y, Sun PL et al (2020) Green transition of cultivated land use in the yellow river basin: a perspective of green utilization efficiency evaluation. Land 9(12):475

Ma XN, Zhang MJ, Wang SJ et al (2012) Evaporation paradox in the Yellow River basin. Acta Geogr Sin 67(5):71-82

Ma Y, Liu ZZ (2021) Study on the spatial-temporal evolution and influencing factors of land use carbon emissions in the yellow river basin. Ecol Econ 37(07):35-43

Miao Z, Chen XD et al (2019) Atmospheric environmental productivity across the provinces of China: joint decomposition of range adjusted measure and Luenberger productivity indicator. Energy Policy 132:665-677 
Miao Z, Chen XD et al (2021) Improving energy use and mitigating pollutant emissions across "three regions and ten urban agglomerations": a city-level productivity growth decomposition. Appl Energy 283:116296

NBSC (2015) China City statistical yearbook. China Statistics Press, Beijing

Ramanathan R (2002) Combining indicators of energy consumption and $\mathrm{CO} 2$ emissions: a cross-country comparison. Int J Glob Energy Issues 17(3):214-227

Shen LY, Wu Y, Lou YL et al (2018) What drives the carbon emission in the Chinese cities? - a case of pilot low carbon city of Beijing. J Clean Prod 174:343-354

Sun XM, Zhang HT, Ahmad M, Xue CK (2021) Analysis of influencing factors of carbon emissions in resource-based cities in the Yellow River basin under carbon neutrality target. Environ Sci Pollut Res Int 24. https://doi.org/10.1007/s11356-021-17386-6

Teng XY, Liu FP, Chiu YH (2021) The change in energy and carbon emissions efficiency after afforestation in China by applying a modified dynamic SBM model. Energy 216:119301

Tone K, Toloo M, Izadikhah M (2020) A modified slacks-based measure of efficiency in data envelopment analysis. Eur J Oper Res 287(2):560-571

Wang CJ, Miao Z, Chen XD, Cheng Y (2021) Factors affecting changes of greenhouse gas emissions in Belt and Road countries. Renew Sustain Energy Rev 147:111220

Wang HP, Wang MX (2020) Effects of technological innovation on energy efficiency in China: evidence from dynamic panel of 284 cities. Sci Total Environ 709:136172

Wang JY, Wang SJ, Li SJ et al (2019) Evaluating the energy-environment efficiency and its determinants in Guangdong using a slackbased measure with environmental undesirable outputs and panel data model. Sci Total Enviro 663:878-888

Wang P, Deng XZ, Zhang N, Zhang XY (2019) Energy efficiency and technology gap of enterprises in Guangdong province: a meta-frontier directional distance function analysis. J Clean Prod 212(C):1446-1453

Wang W, Zhang YY, Tang QH (2020) Impact assessment of climate change and human activities on streamflow signatures in the Yellow River basin using the Budyko hypothesis and derived differential equation. J Hydrol 591(7401):125460

Wang ZH, He WJ (2017) CO 2 emissions efficiency and marginal abatement costs of the regional transportation sectors in China. Transp Res Part D 50:83-97

Wei JX, Lei YL, Yao HJ et al (2021) Estimation and influencing factors of agricultural water efficiency in the Yellow River basin, China. J Clean Prod 308:127249

Xi JP (2021) Building on past achievements and launching a new journey for global climate actions. The Belt and Road Reports 1:20-21

Xu Y, Park YS, Park JD, Cho W (2021) Evaluating the environmental efficiency of the U.S. airline industry using a directional distance function DEA approach. J Manag Anal 8(1):1-18
Xue LM, Zhang WJ, Guo XH et al (2021) Measurement and influential factors of the efficiency of coal resources of China's provinces: based on Bootstrap-DEA and Tobit. Energy 221:119763

Yang F, Wang DW, Zhao LL, Wei FQ (2021) Efficiency evaluation for regional industrial water use and wastewater treatment systems in China: a dynamic interactive network slacks-based measure model. J Environ Manag 279:111721

Yuan MX, Zhao L, Lin A et al (2020) How do climatic and non-climatic factors contribute to the dynamics of vegetation autumn phenology in the Yellow River Basin, China? Ecol Indic 112:106112

Yuan XL, Sheng XR, Chen LP et al (2022) Carbon footprint and embodied carbon transfer at the provincial level of the Yellow River basin. Sci Total Environ 803(1):149993

Zhang GX, Su ZX (2020) Analysis of influencing factors and scenario prediction of transportation carbon emissions in the Yellow River basin. Manag Rev 32(12):283-294

Zhang HW (2020) Problems and countermeasures in the protection and development of the Yellow River basin. Yellow River 42(03):1-10+16

Zhang J, Wu GY, Zhang JP (2004) The estimation of China's provincial capital stock:1952-2000. Econ Res J 10:35-44

Zhang S, Zhang G, Ju H (2020) The spatial pattern and influencing factors of tourism development in the Yellow River basin of China. PLOS ONE 15(11):0242029

Zhang X (2013) Regional allocation of CO2 emissions allowance over provinces in China by 2020. Energy Policy 54:214-229

Zhang YJ, Hao JF (2017) Carbon emission quota allocation among China's industrial sectors based on the equity and efficiency principles. Ann Oper Res 255(1-2):117-140

Zhang ZX (2021) Impact of environmental regulation on industrial green efficiency_- based on non-radial SBM model. J Phys: Conf Ser 1744(4):042179

Zhao J, Xiu H, Wang M et al (2020) Construction of evaluation index system of green development in the Yellow River basin based on DPSIR model. IOP Conf 510:32033

Zhou P, Ang BW, Han JY (2010) Total factor carbon emission performance: a Malmquist index analysis. Energy Econ 32(1):194-201

Zhou P, Sun ZR, Zhou DQ (2014) Optimal path for controlling CO2 emissions in China: a perspective of efficiency analysis. Energy Econ 45(9):99-110

Zhou ZX, Wu HQ, Song PF (2019) Measuring the resource and environmental efficiency of industrial water consumption in China: a non-radial directional distance function. J Clean Prod 240(C): 118169

Zhuang M, Yong G, Sheng JC (2016) Efficient allocation of CO2 emissions in China: a zero-sum gains data envelopment model. Journal of Cleaner Production 112(1):4144-4150

Publisher's note Springer Nature remains neutral with regard to jurisdictional claims in published maps and institutional affiliations. 